Article

\title{
Economic Growth and Expansion of China's Urban Land Area: Evidence from Administrative Data and Night Lights, 1993-2012
}

\author{
John Gibson *, Chao Li and Geua Boe-Gibson \\ Department of Economics, University of Waikato, Private Bag 3105, Hamilton 3240, New Zealand; \\ E-Mails: c195@students.waikato.ac.nz (C.L.); geuaboe@waikato.ac.nz (G.B.-G.) \\ * Author to whom correspondence should be addressed; E-Mail: jkgibson@waikato.ac.nz; \\ Tel.: +64-7-838-4289; Fax: +64-7-838-4331.
}

External Editor: Yu-Pin Lin

Received: 22 August 2014; in revised form: 23 October 2014 / Accepted: 31 October 2014 / Published: 6 November 2014

\begin{abstract}
The relationship between economic growth, expansion of urban land area and the broader issue of cultivated land conversion in China has been closely examined for the late 1980s and 1990s. Much less is known about recent urban expansion and if the effects of economic growth on this expansion have changed over time. This paper updates estimates of urban expansion for China and examines the relationship with city economic growth for 1993-2012. To see if patterns are robust to different types of evidence, administrative data on the area of 225 urban cores are compared to estimates of brightly lit areas from remotely sensed night lights. The trend annual expansion rate in lit area is $8 \%$ and was significantly faster in the decade to 2002 than in the most recent decade. Expansion is slower according to administrative data, at just 5\% per annum, with no change in unconditional expansion rates between decades, while conditional expansion rates have declined. The elasticity of area with respect to city economic output is about 0.3 . Over time, expansion of urban land area is becoming less responsive to the growth of the local non-agricultural population.
\end{abstract}

Keywords: economic growth; land conversion; luminosity; urbanization; China 


\section{Introduction}

The relationship between economic growth, expansion of urban land area and the broader issue of cultivated land conversion in China during the late 1980s and 1990s has been examined in a series of national-level studies [1-3]. Urban land area expanded three percent for every 10 percent increase in local economic output (county gross domestic product (GDP)), and GDP growth fully accounted for all urban expansion from 1995 to 2000. This income elasticity of the urban area is less than that in a global sample of cities [4], indicating the dense nature of urban development in China.

Yet despite these findings, recent policy discussion suggests that urbanization in China relies excessively on land conversion and land financing, causing inefficient urban sprawl [5]. Moreover, recent studies of particular regions argue that the urban form is becoming more dispersed [6], and urban sprawl has increased since the beginning of the 21 st century [7], which is after the period analysed in the existing national-level studies. These more recent studies use the term "sprawl" in the sense of Brueckner [8] as meaning the excessive spatial growth of cities.

Understanding how the rate of urban expansion, and its driving forces, change over time matters to urban planners [3]. Competition for land between urban and other use is very important in China. Land for agricultural and forestry production is concentrated in monsoon-affected East China, where agricultural soils account for 30\% of total land surface; more than 20\% higher than in West China [9]. Since the most rapid economic and urban growth has also been in East China, there are concerns that rates of land conversion may be so high as to endanger aspects of sustainable development, such as food security [5].

The current study provides updated national-level evidence on urban expansion in China and on the effects of local economic growth and population change on this expansion. The 1993-2012 period is examined. Tests are conducted to see if trend expansion rates and the relationship between local economic growth and city area change between the two decades studied. Two types of data are used to see if patterns are robust to different sources of evidence. The first is administrative data from various yearbooks (documented more fully in Section 2 below) that annually report area and various socio-economic indicators for all urban districts in China. There are doubts about yearbook data on the urban area supplied by local governments, since land sales account for up to one quarter of their revenue and not all sales are sanctioned by upper levels of government. For example, in the secondary market, an entity who obtains land use rights from a local government may rent or mortgage that land to others, and this often involves a change in land use that is not registered with the authorities [10].

The second source of data is remotely-sensed night lights. Artificial light is commonly present wherever urban areas occur, and even though night light provides a potentially less accurate measure than the Landsat data used by the prior national-level studies [1-3], lights have the advantage of being low-cost and up-to-date. Night lights should be especially useful for studying urban growth in China, since almost all households were electrified by the start of the study period, with urban electrification rates of $94 \%$ in 1992 and $95 \%$ by 1999 (rural electrification rates were just as high) [11]. Thus, it is not the case that lit areas were catching up to the urban boundary due to rising electrification rates, as may have occurred in other developing countries, such as India.

In addition to the search for robustness from using two different sources of data on urban area and the timeliness of the current study, one other feature is worthy of mention. There are up to 20 years of 
annual data (and 32 satellite-year observations) for each city in the sample. Repeated information over time allows the use of panel data to account for unobservable factors, like environmental conditions (e.g., slope and soil) and local variation in the implementation of urban policy. Even though these factors may reflect the historical legacy of a city and may be related to current land area, their omission from our study does not cause bias. With repeated information over time, one can use "fixed effects" to control for unobserved factors, allowing unbiased estimation [3]. Furthermore, panel data methods allow satellite fixed effects to be used to ameliorate the effects of random measurement error in the estimates of urban area caused by various shortcomings of the Defense Meteorological Satellite Program's Operational Linescan System (DMSP/OLS) sensors for urban mapping. Of the 11 shortcomings considered in the literature [12], the lack of on-board calibration and failure to record gain changes when the signal is amplified to enhance visual interpretation of clouds may introduce the largest temporal errors.

\section{Data and Methods}

This is a national-level analysis covering urban districts (Shiqu) of almost all prefectural cities in China. In the 2010 census, China's 287 prefectural cities had $95 \%$ of the non-agricultural population, with the rest in other types of spatial units, such as banners, leagues and autonomous regions. The westernmost provinces of Xinjiang and Tibet had just three prefectural cities with urban districts (Lhasa, Karamay and Urumqi), and data for these cities are either absent in some official tabulations or reflect a skewed economic structure [13]. We therefore excluded areas west of Gansu when using national-level databases. The main sources for these databases were various issues of the city statistical yearbook [14], hukou yearbook [15] and 50 years of cities [16]. These data are referred to as coming from yearbooks, to distinguish them from the estimates obtained from remote sensing.

A prefectural city typically includes rural counties and county-level cities along with urban districts. The district (or adjacent districts for multi-district prefectures) best proxies for an urban core [17]. These urban cores will be referred to as "cities" in what follows, and in this usage, it does not mean the entire prefectural city. Some districts had been upgraded from previously being banners, leagues, regions or autonomous prefectures and did not always have a continuous time series of data. The yearbooks provide estimates since 1993 and currently run to 2012, so a threshold was set that a city needed data for at least 15 of these 20 years to be in the sample; this excluded 24 of the urban cores. Figure 1 shows the 24 cities excluded and the remaining 260 cities.

In addition to yearbook data, remotely-sensed night lights from the Defense Meteorological Satellite Program's Operational Linescan System (DMSP/OLS) are used. These data are described by Elvidge et al [12] and are available for download. Data are from six satellites: F10 (1992-1994), F12 (1994-1999), F14 (1997-2003), F15 (2000-2007), F16 (2004-2009), F18 (2010-2012). There is a long history of using satellite-detected luminosity to measure urban area (see, for example, [17-25]). The data from DMSP/OLS are reported in relative brightness terms, as a six-bit digital number (DN) ranging from 0-63. A threshold level of brightness can be set to exclude low-lit areas of sparse development. The stable lights annual composite from DMSP/OLS covers 1992-2012, but to match with the time-series of yearbook data, the sample is restricted to 1993-2012. Tests of whether expansion rates for 1993-2002 differ from those for 2003-2012 are conducted. 
Figure 1. Location of urban cores in the sample and urban cores excluded due to incomplete data.

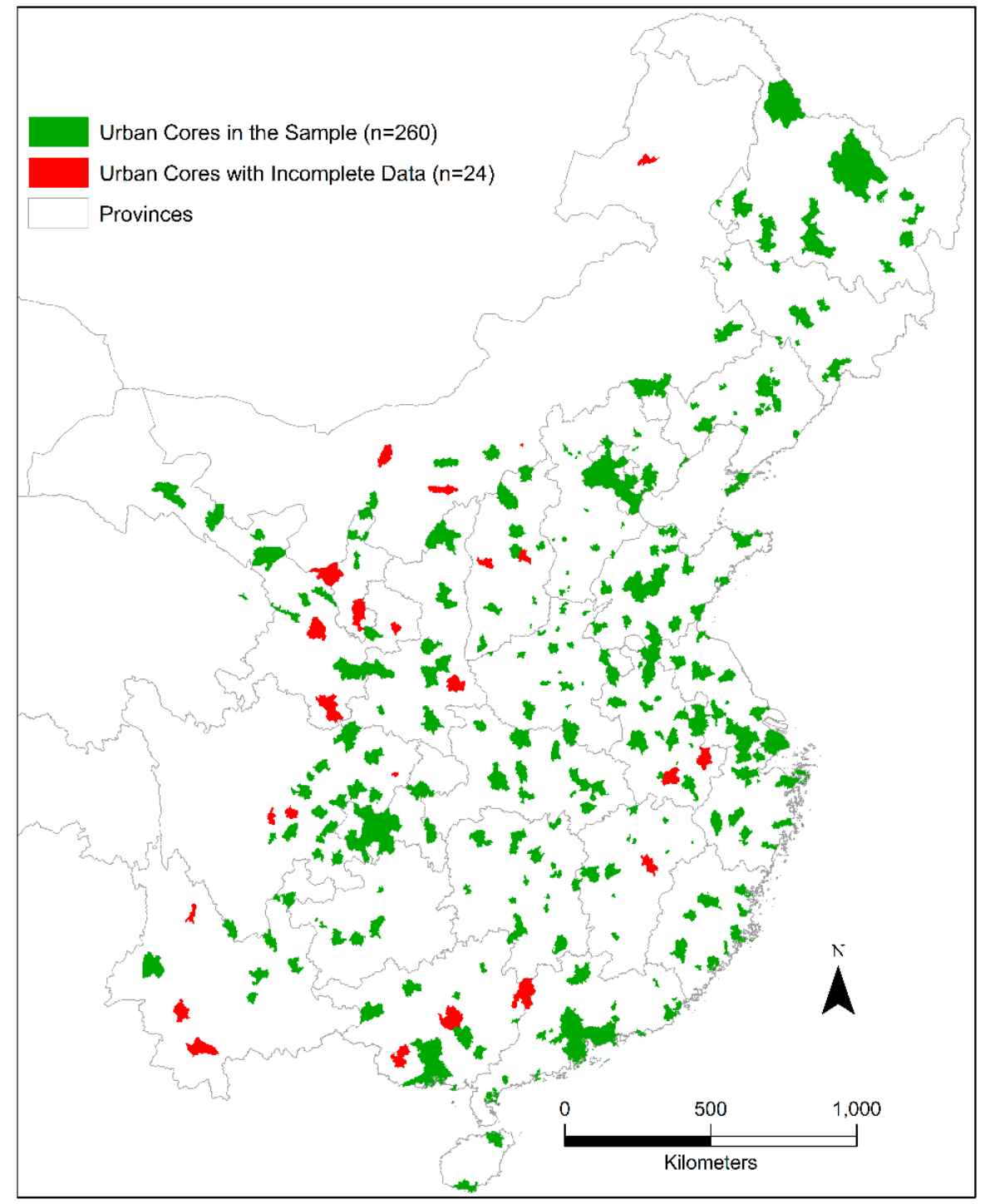

Prior national-level studies of urban expansion and land conversion in China mostly relied on Landsat data [1-3]. In comparison to Landsat, the DMSP stable lights data tend to make agglomerations appear larger. The composites produced by averaging several overlapping input pixels are approximately 1000 times larger than Landsat TM pixels, so sub-pixel light sources are attributed to an expanded area [22]. The reflectance of light from surrounding water and non-urban land (e.g., due to snow or ice) gives a blooming effect [21]. Furthermore, uncertainty in the geo-location that gets compounded by averaging over multiple nights causes exaggeration [23]. However, the proportionate effects are small for medium to large settlements [24]. The urban cores studied here had an average resident population of 1.6 million and a minimum population of 0.2 million in the 2010 census, so errors for cities of this scale should be relatively small. Therefore, there is a strong linear trend between night lights and traditional measures of urban area in China [25]. The results reported below use both administrative data on urban area and night lights to indicate if the findings on urban expansion rates and their driving forces are robust.

A key decision with night lights is the brightness threshold to classify a pixel as urban. A lower detection threshold makes urban areas seem larger, and cities may merge if linked by built-up corridors along major transport routes. Figure 2 gives examples of this effect for some cities in Central China. 
In this figure and the results below, the digital numbers are in percent of the maximum value $(\mathrm{DN}=63)$, to stress that they are relative rather than absolute values. In Figure 2, the thresholds are $90 \%, 60 \%$ and $30 \%$. These thresholds work as follows: starting from the centre of each city, where lights are brightest, and moving outwards, as the algorithm finds pixels less illuminated than the threshold, it begins searching in a different direction. If the algorithm finds no adjacent pixels lit above the threshold, except those already scanned closer to the city centre, it sets a boundary. Prior studies of night lights in China use specific DN thresholds that are as low as 5, 8 and 12 [24] and as high as 27 to 62 [26]. The thresholds in Figure 2 correspond to DN values of 56, 37 and 19. There is no consensus on the particular threshold to use, so criteria for choosing a threshold are considered below, and two thresholds are chosen, to ensure that the results are not sensitive to the threshold used.

Figure 2. Examples of the effect of luminosity thresholds on apparent urbanized area and the number of distinct urban cores, from (a) Henan and (b) Hunan, China (Satellite F18 2012).

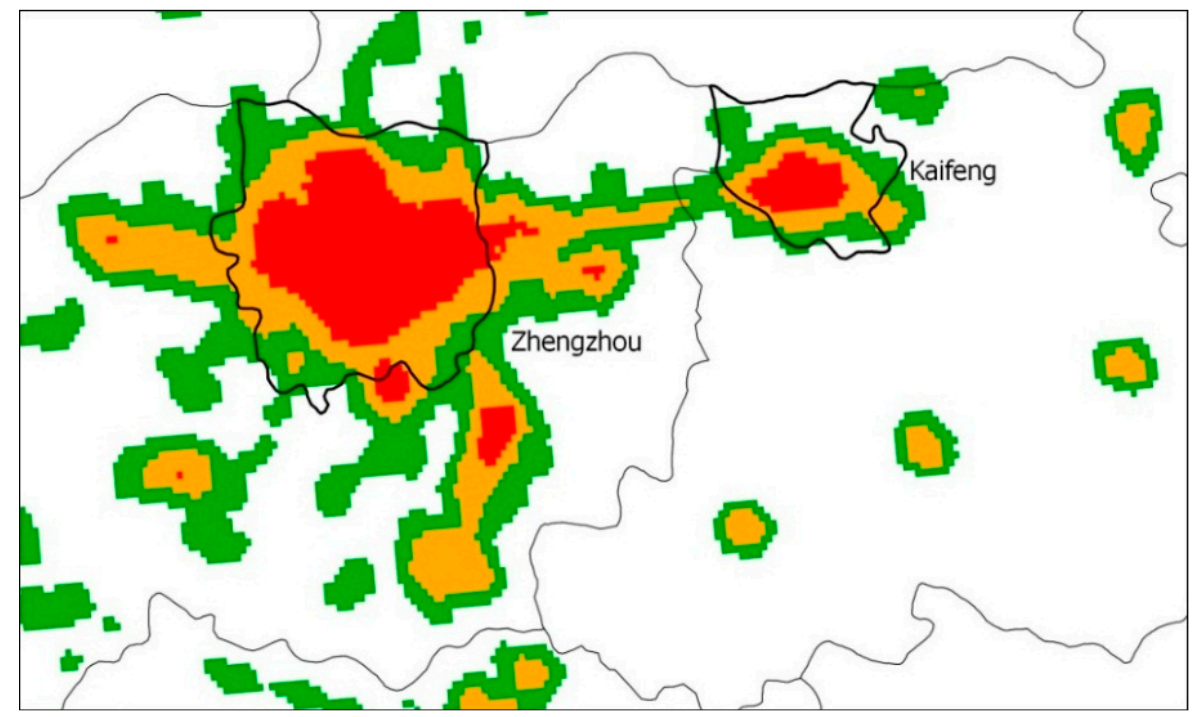

(a)

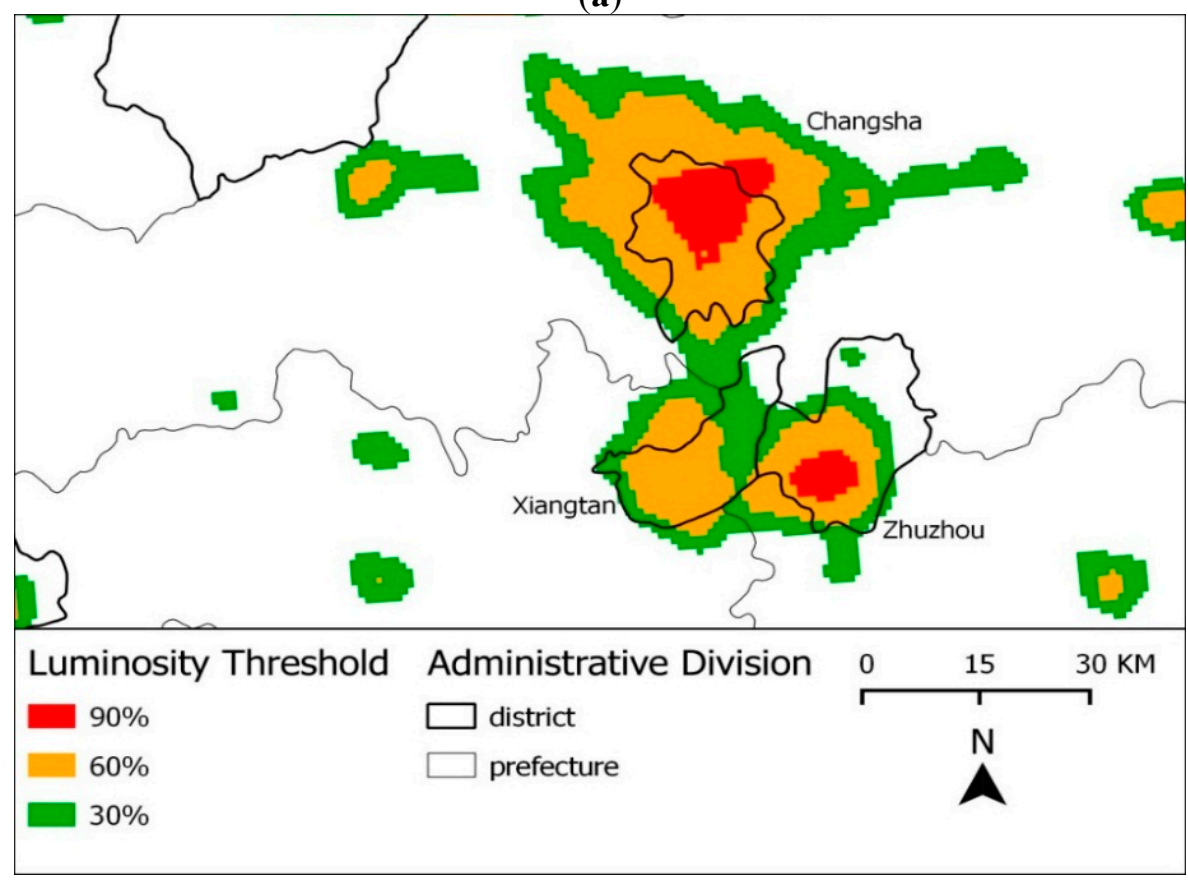

(b) 
In Figure 2a, the nearby cities of Zhengzhou and Kaifeng (64 kilometres apart) form a single urban area if a lower luminosity threshold is used, because a highly lit corridor about five kilometres wide joins them. At higher thresholds, they shrink into separate "islands", and at 90\%, even a city of eight million, like Zhengzhou, has substantial areas not classified as urban. The example in Figure $2 \mathrm{~b}$ has three nearby urban cores joined when a $30 \%$ luminosity threshold is used, but these become distinct cores at $60 \%$ (plus a small "island" detaches from Changsha). A very high detection threshold causing some cities to disappear entirely is also illustrated; the city of Xiangtan has an apparent area of $200 \mathrm{~km}^{2}$ at a luminosity threshold of $60 \%$, but it disappears at $90 \%$, because its lights are not bright enough, even though it has a population of two million.

The trade-off between high and low thresholds is shown more generally in Figure 3. The total area for cities in the sample is on a $\log$ scale for 1993, 2002 and 2012 at thresholds from $30 \%$ to $100 \%$. The slope changes at about $90 \%$, but at lower thresholds, each percentage ( $0.6 \mathrm{DN}$ points) raises the apparent urban area by $3.8 \%$ in 1993 and 2.5\%, otherwise. The diamond-shaped markers in Figure 3a show total area according to the yearbooks. In 1993, a luminosity threshold of $65 \%$ gives the best match with yearbook data, while in the later years, the best match is at $85 \%$ and $90 \%$. The rise in the threshold that best matches yearbook data implies that yearbook estimates of urban area rise slower than luminosity-based estimates. Specifically, between 1993 and 2012, the area estimates in the yearbooks tripled, while lit area increased by a factor of 7.5 at a $65 \%$ luminosity threshold and by more at higher thresholds. The likelihood is that yearbook data on urban areas are under-estimated due to the incentives facing local governments [10]. This under-estimate has been observed by the remote-sensing literature, where it is suggested that the differences reflect limitations in the techniques used to gather the yearbook data [26].

Returning to the question of the choice of luminosity threshold, anything above $65 \%$ gives a smaller area in 1993 than what the yearbook data show. Local governments are unlikely to overstate urban area, given concerns from higher levels of government about converting farm land [10]. Thus, we do not use any luminosity thresholds above $65 \%$, since these give a smaller urban area at the start of our study period than what the yearbooks report. High thresholds also make less brightly-lit cities drop out of the sample (Figure 3b). However, the number of observations also falls at low thresholds, as nearby cities clump into single units. Luminosity thresholds from 50\% to $65 \%$ maximise observations and give similar estimates of area at the start of the period to what yearbook data show. To see if patterns are robust to different ways of measuring areas, the results use city area reported in the yearbooks and also use area estimates from night light at luminosity thresholds of $50 \%$ and $65 \%$.

When cities clump into a single unit, the time series of the lit area is interrupted. Figure 4 shows (a) the Yangtze Delta and (b) the Pearl River Delta. By 2011, the separate cities in each delta had joined at a luminosity threshold of 50\%, but several of them were separate in earlier years, as shown for 2005 . To provide consistent time series, any cities that eventually join together at the $50 \%$ luminosity threshold are joined for all years (1993-2012) and for all three samples: the estimates from yearbook data and the lit area estimates from the $50 \%$ and $65 \%$ thresholds. This gives consistent samples across years and data sources. After these merges, the number of cities in the sample drops from $n=260$ to $n=225$ (but they continue to cover the same total area). 
Figure 3. The effect of varying luminosity thresholds for detecting urban boundaries on (a) apparent urban area and (b) the number of cities separately distinguished.

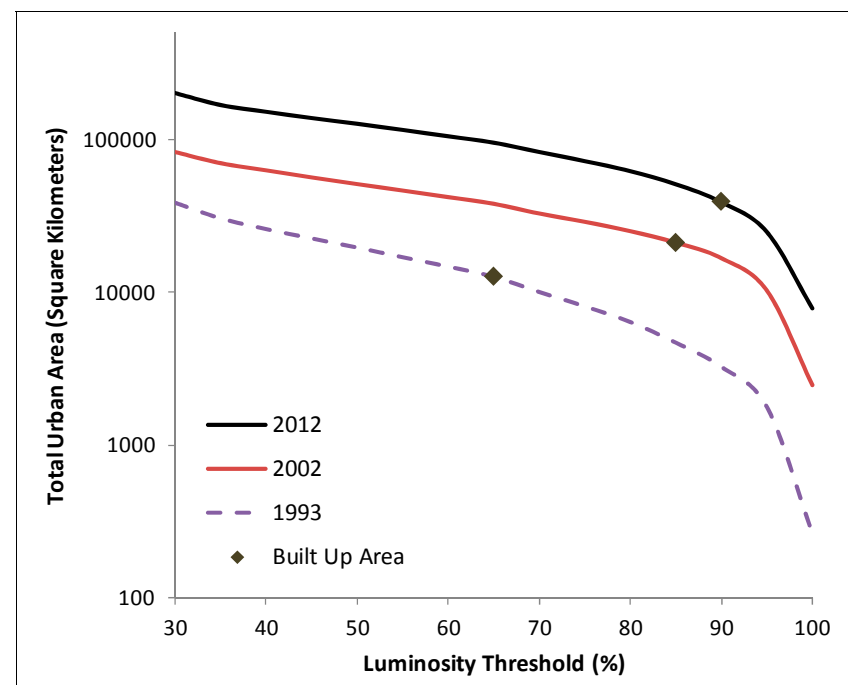

(a)

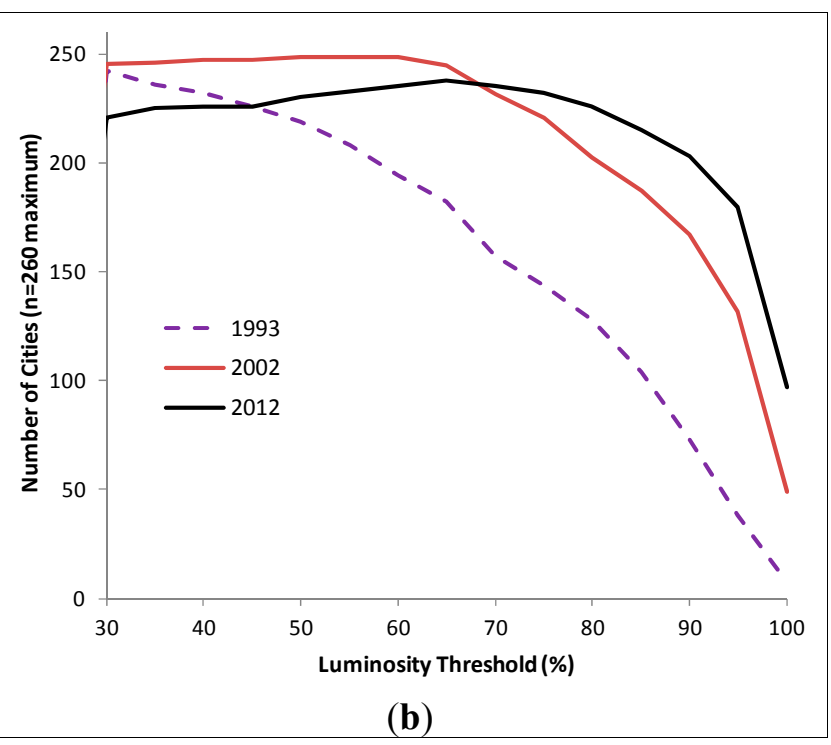

(b)

Figure 4. The joining of initially separate cities in the (a) Yangtze Delta and (b) Pearl River Delta.

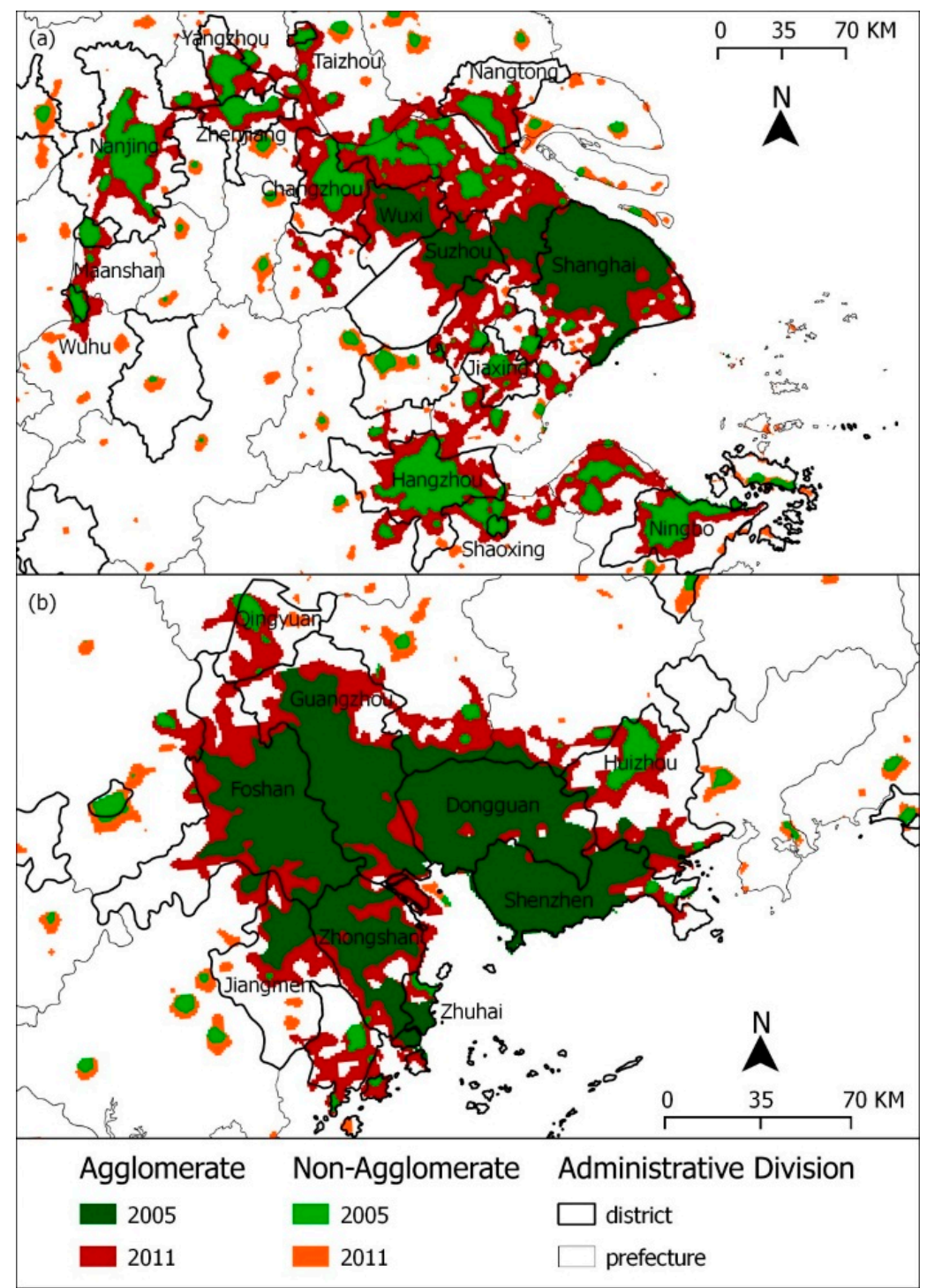


The final modelling issue is how to deal with temporal measurement error in night light data. The DMSP/OLS sensors lack on-board calibration, and no record is kept of gain changes (when the signal is amplified to help the U.S. Air Force detect clouds). These features introduce temporal variability into the record from a given satellite. Furthermore, in years that two satellites are in orbit (e.g., 1994 and 1997-2007), a stable lights composite from one satellite's passes over a given area during the year will not be the same as the composite for the same area from the other satellite. This "noise" is undesirable, but random error in a dependent variable does not cause estimator bias and is unlikely to overwhelm the "signal" in the data from the true, but unknown, expansion of the urban area.

One way to deal with inter-satellite variation is to average values in years with two satellites [27]. Another is inter-calibration, with regression adjustment to DN data prior to use in an analysis [28]. For the most widely-used calibrated data, the F12 satellite in 1999 is treated as "truth", because it has the highest DN values across years and satellites. Regressions of these 1999 DN values on a polynomial of $\mathrm{DN}$ values from other years and satellites for each pixel on the island of Sicily (which is assumed to be temporally stable) are used to generate sets of coefficients [23]. The DN values from the other years and other satellites are then plugged into this regression to adjust the raw DN values to match the values from F12 in 1999. This calibration can also be done for a particular country or region and has been done for China [26]. However, whether local or global, calibration relies on untested assumptions about temporal and spatial homogeneity. Moreover, subsequent analysis of adjusted values should take into account the fact that these are predictions from a regression, and so, when they are treated as data, the standard errors should be adjusted for the two-stage estimation.

In contrast to these methods, this study does not average and does not calibrate. Instead, the (log) area of urban core $i$ in year $t$, as measured by satellite $s$, is modelled with a fixed effects regression:

$$
\ln A_{i t s}=\beta_{0}+\beta_{1} T+\delta_{s} D_{s}+\gamma_{i} D_{i}+\varepsilon_{i t s}
$$

where $T$ is a time trend, $D_{s}$ is a set of fixed effects for each satellite, $D_{i}$ is a set of fixed effects for each urban core and $\varepsilon_{i t s}$ is a random error. The $\hat{\beta}_{1}$ gives the percentage change in area for a one unit increase in $T$ and, so, is the best estimate of the trend annual rate of expansion, after controlling for the characteristics of each city and the idiosyncratic characteristics of each satellite. Unlike averaging observations in years with two satellites, which gives equal weight to both, the regression approach uses data-determined weights (the size of the $\hat{\delta}_{s}$ ). The measurement errors in the $A_{i t s}$ should be random, conditional on $D_{s}$, so that they go into the residuals, $\hat{\varepsilon}_{i t s}$, and do not bias coefficient estimates (but do create heteroscedasticity, so robust variance estimators should be used).

Equation (1) can also be extended to test if the growth rate is changing over time, using either a quadratic trend model or a piecewise linear trend. A dummy variable for the second decade in the study period $D_{t}$ can be interacted with the time variable to give a piecewise trend:

$$
\ln A_{i t s}=\beta_{0}+\beta_{1} T+\lambda\left(T \times D_{t}\right)+\gamma D_{t}+\delta_{s} D_{s}+\gamma_{i} D_{i}+\varepsilon_{i t s}
$$

A test of the null hypothesis $\lambda=0$ is a test of whether the trend annual rate of expansion is changing over time, while the annual expansion rate for the second period is calculated as: $\hat{\beta}_{1}+\hat{\lambda}$.

The fixed effects regression can also be further extended to allow for time-varying covariates. The two covariates considered here are city economic output (GDP) and non-agricultural population (POP). 


$$
\ln A_{i t s}=\beta_{0}+\beta_{1} T+\beta_{2} \ln G D P_{i t}+\beta_{3} \ln P O P_{i t}+\delta_{s} D_{s}+\gamma_{i} D_{i}+\varepsilon_{i t s}
$$

With fixed effects for both cities and satellites included, the estimated elasticities from Equation (3) are unlikely to be biased by the presence of unobserved factors that affect city area and correlate with local economic output or local population. In order to examine how these elasticities change over time, the dummy variable for the second decade in the observation period, $D_{t}$, can be added to the model and interacted with the time-varying covariates and with the linear time trend.

\section{Results}

\subsection{Trend Expansion Rates for Urban Cores}

The results of estimating Equation (1) are reported in Table 1. The main results use a luminosity threshold of $65 \%$, and a sensitivity analysis uses a threshold of $50 \%$. These cities are expanding at a trend annual rate of $8.3 \%$ at the preferred threshold for defining a pixel as part of the urban core. The expansion rate is slightly less $(8.0 \%)$ if the $50 \%$ luminosity threshold is used, which is to be expected, since the lower detection threshold gives a larger apparent urban area to start with, and so, subsequent growth rates are then lower. At these trend rates of expansion, China's urban cores would be expected to double in area after nine years. However, the rate of city expansion appears to be slowing down, which is shown in Table 1 by the statistically significant negative coefficient on the squared term for a quadratic time trend (Panel B). This slowing of the expansion rate is also shown by the negative deviation term when a piecewise trend is estimated (Panel C). Specifically, allowing the time trend to differ from the first decade (1993-2002) to the second decade (2003-2012), there is a statistically significant fall in the annual rate of expansion of at least six percentage points between the periods. Thus, while the rate of area expansion for these cities in the first decade was around eleven percent per annum, in the second decade, it was only around five percent per annum.

The results in Table 1 control for fixed characteristics of cities and of satellites. Both sources of variation in the apparent area of a city-satellite-year cell matter, given the statistically significant $F$-test results for the joint hypotheses that each set of fixed effects can be excluded from the model. These results are in the columns headed "cities" and "satellites". One sensitivity analysis that does not seem to matter is if sample values are weighted to reflect the fact that some observations represent more than one of the original urban cores (in cases where two or more cities merge into one, as seen in Figure 4). Unreported results for urban areas as defined at the $65 \%$ luminosity threshold that use weights are very similar to what is in Table 1; the linear trend is $8.4 \%$ rather than $8.3 \%$, and the two values for the piecewise trend are $11.5 \%$ and $-7.3 \%$, rather than $11.6 \%$ and $-7.5 \%$.

While the results using the two luminosity thresholds are quite consistent with each other, they are rather different from the results obtained when using the yearbook data on the urban area. The linear trend model suggests an annual rate of expansion in yearbook-reported urban area for these 225 cities of just $5.1 \%$ rather than the trend annual increase of $8.3 \%$ that the luminosity data suggest. This slower growth rate implies a doubling time of 15 years rather than the nine years that the night lights data show. The supposition in the literature is that local governments may have incentives to under-report land conversion to urban uses [10]. The empirical pattern that the yearbook estimates of urban area are less than what remote sensing data indicate [26] is supported by our findings, since the rate of expansion is 
less when using the yearbook data. In addition to the difference in the trend annual rates of expansion, when the yearbook data are used with the quadratic and piecewise trend models, there is no evidence of a slowing in the growth rate of city land area in the later years of the observation period. However, it should be noted that this inconsistency, compared with the robust finding from the night light data of a slowdown in the expansion rate for the decade since 2002, is less apparent once other covariates are added to the models, as discussed in the next section.

Table 1. Average trend expansion rates for urban cores in China, 1993-2012.

\begin{tabular}{|c|c|c|c|c|c|c|}
\hline & \multirow{2}{*}{$65 \%$ Threshold } & \multicolumn{2}{|c|}{ Fixed Effects $=0$} & \multirow{2}{*}{$R^{2}$} & \multirow{2}{*}{$\begin{array}{c}50 \% \\
\text { threshold }\end{array}$} & \multirow{2}{*}{$\begin{array}{c}\text { Yearbook } \\
\text { data on area }\end{array}$} \\
\hline & & Cities & Satellites & & & \\
\hline \multicolumn{7}{|l|}{ Panel A: Linear Trend } \\
\hline Trend Expansion Rate & $\begin{array}{c}8.3 \% \\
(25.1)^{* * *} \\
\end{array}$ & $583 * * *$ & $125 * * *$ & 0.908 & $\begin{array}{c}8.0 \% \\
(26.6) * * * \\
\end{array}$ & $\begin{array}{c}5.1 \% \\
(29.6) * * * \\
\end{array}$ \\
\hline \multicolumn{7}{|c|}{ Panel B: Quadratic Trend } \\
\hline Linear term & $\begin{array}{l}12.70 \\
(6.69) * * *\end{array}$ & $571 * * *$ & $122 * * *$ & 0.909 & $\begin{array}{c}8.65 \\
(5.34) * * *\end{array}$ & $\begin{array}{c}-0.87 \\
(1.26) \\
\end{array}$ \\
\hline Squared term $\times 100$ & $\begin{array}{l}-0.32 \\
(6.65) * * *\end{array}$ & & & & $\begin{array}{l}-0.21 \\
(5.29) * * *\end{array}$ & $\begin{array}{c}0.02 \\
(1.34) \\
\end{array}$ \\
\hline \multicolumn{7}{|c|}{ Panel C: Piecewise Trend } \\
\hline Trend 1993-2002 & $\begin{array}{l}11.6 \% \\
(18.0) * * *\end{array}$ & $565 * * *$ & $152 * * *$ & 0.910 & $\begin{array}{l}10.9 \% \\
(19.6) * * *\end{array}$ & $\begin{array}{c}4.5 \% \\
(17.3) * * * \\
\end{array}$ \\
\hline Deviation 2003-2012 & $\begin{array}{l}-7.5 \% \\
(8.4) * * *\end{array}$ & & & & $\begin{array}{l}-5.7 \% \\
(7.4) * * *\end{array}$ & $\begin{array}{l}0.5 \% \\
(1.4)\end{array}$ \\
\hline
\end{tabular}

Notes: Trends are estimated from variants of Equation (1). Fixed effects for cities and satellites not reported. The $t$-statistics for trends in ( ) and $F$-statistics for fixed effects $=0$ are from robust standard errors. Statistical significance at the $90 \%, 95 \%$ and $99 \%$ level is denoted by $*, * *, * * * . N=225$ urban cores.

\subsection{The Elasticity of Urban Area With Respect to City Economic Output}

The area of these urban cores that is reported in yearbook data increases by $2.7 \%$ for every ten percent rise in city GDP and by 3.7 percent for every ten percent rise in the non-agricultural hukou population of the city (Table 2, Column 1). This sensitivity of the urban area to growth in the local population is quite different from the existing results from national-level studies for China, where it appeared that local population growth had no impact on the rate of expansion [2,3]. If a time trend is included in the regression, it substantially reduces the elasticity of the urban area with respect to city GDP, but not with respect to the non-agricultural population of the city. As for changes in the elasticities over time, the results in Columns 3 and 4 show that the urban area was more elastic with respect to economic output and less elastic with respect to local population in the period after 2002 than before then. The trend rate of urban expansion, conditional on population and local economic output, also was significantly lower in this second decade of the observation period. This fall in the (conditional) expansion rate is in keeping with the main result of a slowing expansion rate that was found in Table 1 using night light-derived measures of city area. 
Table 2. The effects of GDP and population on the expansion of urban area in China, 1993-2012.

\begin{tabular}{|c|c|c|c|c|}
\hline & \multicolumn{4}{|c|}{ Dependent variable: $\ln ($ area, city $i$ year $t$ ) from Yearbook data } \\
\hline & (1) & (2) & (3) & (4) \\
\hline \multirow[t]{2}{*}{$\ln ($ GDP for city $i$ in year $t$ ) } & 0.266 & 0.175 & 0.160 & 0.085 \\
\hline & $(15.94) * * *$ & $(5.38) * * *$ & $(6.99) * * *$ & $(2.07) * *$ \\
\hline \multirow[t]{2}{*}{$\ln (\text { non-agricultural population })_{i t}$} & 0.367 & 0.366 & 0.431 & 0.432 \\
\hline & $(5.50) * * *$ & $(5.65) * * *$ & $(6.96) * * *$ & $(7.27) * * *$ \\
\hline \multirow[t]{2}{*}{ Time trend $(t=1,2,3, \ldots T)$} & & 0.014 & & 0.019 \\
\hline & & $(3.06) * * *$ & & $(3.89) * * *$ \\
\hline \multirow[t]{2}{*}{$\ln (\mathrm{GDP})_{i t} \times D_{t}\left(D_{t}=1\right.$ if year $\left.>2002\right)$} & & & 0.122 & 0.160 \\
\hline & & & $(5.24) * * *$ & $(4.91) * * *$ \\
\hline \multirow[t]{2}{*}{$\ln (\text { non-agricultural population })_{i t} \times D_{t}$} & & & -0.107 & -0.144 \\
\hline & & & $(3.51) * * *$ & $(3.71) * * *$ \\
\hline \multirow[t]{2}{*}{ Time trend $\times D_{t}$} & & & & -0.013 \\
\hline & & & & $(2.40) * *$ \\
\hline$R^{2}$ & 0.945 & 0.946 & 0.947 & 0.948 \\
\hline
\end{tabular}

Note: Fixed effects for cities and the overall intercept are not reported. The $t$-statistics in ( ) are from robust standard errors. Statistical significance at the $90 \%, 95 \%$ and $99 \%$ level is denoted by *,**,***. $N=225$ urban cores and 3967 observations.

The estimated elasticities and their change over time appear to be quite different when city area is measured using night lights rather than using administrative data. Specifically, there appears to be no effect of the locally-registered non-agricultural population on urban area (Table 3 , row 2 ). The elasticity of area with respect to city GDP is 0.37 , with cities measured at a luminosity threshold of $65 \%$, (Table 3 , Column 1). These economic output and local population elasticities are quite similar to those reported by Deng and colleagues [2] when using Landsat 5 data on urban areas in the 1990s.

Table 3. The effects of GDP and population on the expansion of urban area in China, 1993-2012.

\begin{tabular}{|c|c|c|c|c|}
\hline & \multicolumn{4}{|c|}{ Dependent variable: In (lit area, city $i$ year $t$ ) with $65 \%$ threshold } \\
\hline & (1) & (2) & (3) & (4) \\
\hline \multirow[t]{2}{*}{$\ln ($ GDP for city $i$ in year $t$ ) } & 0.373 & 0.109 & 0.307 & 0.154 \\
\hline & $(11.95) * * *$ & $(2.38) * *$ & $(6.93) * * *$ & $(3.08) * * *$ \\
\hline \multirow{2}{*}{$\ln (\text { non-agricultural population })_{i t}$} & 0.094 & 0.100 & 0.168 & 0.157 \\
\hline & $(0.94)$ & $(0.90)$ & $(1.57)$ & $(1.41)$ \\
\hline \multirow[t]{2}{*}{ Time trend $(t=1,2,3, \ldots T)$} & & 0.062 & & 0.093 \\
\hline & & $(8.46) * * *$ & & $(11.60) * * *$ \\
\hline \multirow[t]{2}{*}{$\ln (\mathrm{GDP})_{i t} \times D_{t}\left(D_{t}=1\right.$ if year $\left.>2002\right)$} & & & 0.033 & 0.113 \\
\hline & & & $(0.67)$ & $(2.24) * *$ \\
\hline \multirow[t]{2}{*}{$\ln (\text { non-agricultural population })_{i t} \times D_{t}$} & & & -0.158 & -0.237 \\
\hline & & & $(2.57) * *$ & $(3.80) * * *$ \\
\hline \multirow[t]{2}{*}{ Time trend $\times D_{t}$} & & & & -0.097 \\
\hline & & & & $(9.11) * * *$ \\
\hline$R^{2}$ & 0.904 & 0.907 & 0.907 & 0.912 \\
\hline
\end{tabular}

Notes: Fixed effects for cities and satellites and the overall intercept are not reported. The $t$-statistics in ( ) are from robust standard errors. Statistical significance at the $90 \%, 95 \%$ and $99 \%$ level is denoted by $*, * *, * * *$. For the $N=225$ urban cores, there are 6229 city-satellite-year observations. 
When a dummy variable for the second decade is interacted with the other variables, there is no change over time in the elasticity of land area with respect to GDP, but a statistically significant fall in the elasticity with respect to non-agricultural population (Table 3, Column 3). Once a piecewise time trend is added, the second decade shows significantly slower expansion rates than the first decade, conditional on GDP and population. This result is consistent with the finding in Table 1 of a slowdown in the expansion rates in the most recent period. The large fall in the elasticity of land area with respect to local population in the most recent period is still apparent with the time trend included, while the elasticity with respect to GDP appears to rise somewhat (but still is less than 0.3 for 1993-2012).

The patterns of the estimated elasticities and their changes over time are very similar when urban areas are measured with a 50\% luminosity threshold as a sensitivity analysis (Table 4 ). While the elasticity of land area with respect to local population is more precisely estimated in this sensitivity analysis, the magnitude is roughly the same as in Table 3, with urban expansion appearing relatively insensitive to growth in local population. The slowdown in the trend rate of expansion, conditional on population and GDP, remains apparent. Indeed, this significant slowdown in the trend rate of expansion in the second decade of our study is a common finding across Tables 2-4, and so, it is a feature of both the night light data and yearbook data. Other patterns from these two data sources are quite different; for example, in terms of the trend expansion rates. Thus, the fact that the slowdown in expansion over time is shown by both types of data is a notable finding that is presumed to be more robust than if it were apparent only with one type of data.

Table 4. Sensitivity analysis for elasticities using urban core area with a 50\% luminosity threshold.

\begin{tabular}{|c|c|c|c|c|}
\hline & \multicolumn{4}{|c|}{ Dependent variable: In (lit area, city $i$ year $t$ ) with $50 \%$ threshold } \\
\hline & (1) & (2) & (3) & (4) \\
\hline $\ln ($ GDP for city $i$ in year $t)$ & $\begin{array}{c}0.324 \\
(11.64) * * *\end{array}$ & $\begin{array}{l}0.093 \\
(2.25) * *\end{array}$ & $\begin{array}{l}0.259 \\
(6.61) * * *\end{array}$ & $\begin{array}{l}0.095 \\
(2.06) * *\end{array}$ \\
\hline $\ln (\text { non-agricultural population) })_{i t}$ & $\begin{array}{c}0.115 \\
(1.36)\end{array}$ & $\begin{array}{c}0.120 \\
(1.28)\end{array}$ & $\begin{array}{l}0.186 \\
(2.01) * *\end{array}$ & $\begin{array}{c}0.183 \\
(1.87) *\end{array}$ \\
\hline Time trend $(t=1,2,3, \ldots T)$ & & $\begin{array}{l}0.054 \\
(8.84) * * *\end{array}$ & & $\begin{array}{c}0.077 \\
(11.74) * * *\end{array}$ \\
\hline $\ln (\mathrm{GDP})_{i t} \times D_{t}\left(D_{t}=1\right.$ if year $\left.>2002\right)$ & & & $\begin{array}{c}0.068 \\
(1.59) \\
\end{array}$ & $\begin{array}{l}0.114 \\
(2.54) * *\end{array}$ \\
\hline $\ln (\text { non-agricultural population })_{i t} \times D_{t}$ & & & $\begin{array}{l}-0.145 \\
(2.72) * * *\end{array}$ & $\begin{array}{l}-0.187 \\
(3.48) * * *\end{array}$ \\
\hline Time trend $\times D_{t}$ & & & & $\begin{array}{l}-0.058 \\
(7.25) * * *\end{array}$ \\
\hline$R^{2}$ & 0.939 & 0.942 & 0.941 & 0.944 \\
\hline
\end{tabular}

Notes: See Table 3. For the $N=225$ urban cores, there are 6357 city-satellite-year observations using the $50 \%$ threshold. Statistical significance at the $90 \%, 95 \%$ and $99 \%$ level is denoted by $*, * *, * * *$.

\section{Discussion and Conclusions}

The cities studied in this paper are home to the majority of China's urban population. The land area of these cities reflects the demand for living space of this urban population, along with the land needs of commercial and urban industrial development. The increase in China's urban population and the rising 
affluence of that population will see continued expansion of urban area. It is therefore important that agencies concerned with land use and land conversion are aware of the most recent and comprehensive patterns, rather than basing decisions on earlier evidence or more limited case studies.

The current national-level analysis finds consistent evidence that the rate of spatial expansion for these cities is slowing down, and this pattern holds across several different ways of measuring urban area and of modelling expansion. Specifically, if one looks at the expansion of urban land area conditional on local economic output and local population, then all three measures of urban area studied here show a sharp fall in the expansion rate in the decade since 2002. If unconditional expansion rates are studied, then two out of the three indicators of city land area show this slowdown.

This lower expansion rate in the most recent decade may reflect the effects of policy that aimed to direct urbanization elsewhere, such as to county-level cities. For example, the 1990 "City Planning Law" (Zhonghua Renmin Gongheguo Chengshi Guihua Fa) mandated "strictly controlling the size of large cities and developing medium-sized and small cities", and a short-lived county-to-city upgrading system was attempted [29]. This national-level policy, and possible effects of local competition for mobile industry, helped fuel rapid growth in the construction sector that was especially apparent outside of the core urban districts whose spatial expansion is analysed here. For example, the share of the working age population employed in the construction sector doubled between the 2000 and 2010 censuses. Where that construction sector employment was located also shifted [30]; for urban districts, the contribution to total construction sector employment fell from $52 \%$ to $42 \%$, while for counties, it rose from $29 \%$ to $41 \%$. With so much construction employment moving into counties over this decade, it is plausible that the rate of expansion of urban areas in counties was increasing even as expansion rates slowed in the urban cores that house most of China's urban residents.

An additional factor that may have slowed expansion of urban core areas is the effects on China of the Global Financial Crisis (GFC). At the provincial level, the GFC seems to have reduced inequality, with income growth in export-oriented coastal areas slowing [31] and millions of workers moving back to their homes in interior provinces [32]. This demand shock in the middle of the second decade studied here may have reduced the rate of urban expansion in the rapidly growing coastal provinces and possibly shifted the location of expansion towards less urbanized areas in the interior.

In keeping with the existing evidence [2,3], the econometric results reported here suggest that rising income is an important driving force for the expansion of urban areas in China. Nevertheless, the rate of response of land area to local economic growth is fairly modest; the elasticity of 0.3 is well below the global average for the income elasticity of urban land area. Consequently, it remains true that urban areas in China are relatively densely populated when judged by the standards of the rest of the world. While there was some evidence of a more elastic response of land area to economic growth in the second decade of the period studied here, that change was from a low base and was most visible for the yearbook data on built-up area, which exhibits different trends than the night light-derived measures of city area. Moreover, there are grounds for doubting the accuracy of yearbook data, given the possible incentives for local officials to under-report land conversion. A continued monitoring of the response of urban land area to local economic growth would be a useful contribution of future research.

The fall over time in the elasticity of urban land area with respect to local population is not a result that would be expected, based on recent discussions of urban policy in China [5] and recent case study evidence [6]. If rising city population is not translating into expanded city land area, it must be the case 
that the population density of cities is rising, rather than becoming more dispersed, as is often asserted. A possible reason for this unexpected result is that the hukou registered non-agricultural population for each city is becoming a less reliable count of the actual number of city residents, because of the growing number of non-hukou migrants [31]. The count of hukou holders is used in this study and in the previous national-level studies [2,3], because it is the only city-level population count reported annually. It would be a useful topic for future research to form de facto measures of city size based on counting residents rather than the de jure measures based on the hukou count and to test which is the better predictor of city land area. It is helpful for urban planners to find the best way to count people for use in forecasting the future land needs for China's growing urban population.

\section{Acknowledgments}

This research was funded by the Strategic Investment Fund of the University of Waikato. The help of Glen Stitchbury and Susan Olivia with obtaining the data on night lights is gratefully acknowledged, as are the suggestions by three anonymous reviewers.

\section{Author Contributions}

The first and corresponding author, John Gibson, designed the research and wrote the initial text of the paper. Chao Li and Geua Boe-Gibson were responsible for the processing and analysis of the remote sensing data and the production of the maps. Chao Li gathered all of the administrative data from the various yearbooks. All authors read and approved the final manuscript.

\section{Conflicts of Interest}

The authors declare no conflict of interest.

\section{References}

1. Deng, X.; Huang, J.; Rozelle, S.; Uchida, E. Cultivated land conversion and potential agricultural productivity in China. Land Use Policy 2006, 23, 372-384.

2. Deng, X.; Huang, J.; Rozelle, S.; Uchida, E. Growth, population and industrialization, and urban land expansion of China. J. Urban Econ. 2008, 63, 96-115.

3. Deng, X.; Huang, J.; Rozelle, S.; Uchida, E. Economic growth and the expansion of urban land in China. Urban Stud. 2010, 47, 813-843.

4. Angel, S.; Sheppard, S.; Civco, D.; Buckley, R.; Chabaeva, A.; Gitlin, L.; Kraley, A.; Parent, J.; Perlin, M. The Dynamics of Global Urban Expansion. Avaliable online: http://siteresources.worldbank.org/INTURBANDEVELOPMENT/Resources/dynamics_urban_ex pansion.pdf (accessed on 22 August 2014).

5. Urban China: Toward Efficient, Inclusive, and Sustainable Urbanization. Avaliable online: https://openknowledge.worldbank.org/handle/10986/18865 (accessed on 22 August 2014).

6. Zeng, C.; He, S.; Cui, J. A Multi-Level and Multi-Dimensional Measuring on Urban Sprawl: A Case Study in Wuhan Metropolitan Area, Central China. Sustainability 2014, 6, 3571-3598. 
7. Li, J.; Deng, J.; Wang, K.; Li, J.; Huang, T.; Lin, Y.; Yu, H. Spatiotemporal Patterns of Urbanization in a Developed Region of Eastern Coastal China. Sustainability 2014, 6, 4042-4058.

8. Brueckner, J.K. Urban sprawl: Diagnosis and remedies. Int. Reg. Sci. Rev. 2000, 23, 160-171.

9. Chen, J. Rapid urbanization in China: A real challenge to soil protection and food security. Catena 2007, 69, 1-15.

10. World Bank. China's Urbanization and Land-A Framework for Reform. Avaliable online: http://www.worldbank.org/content/dam/Worldbank/document/EAP/China/Urban-China-SRs4-7.pdf (accessed on 22 August 2014).

11. Pachauri, S.; Jiang, L. The household energy transition in India and China. Energy Policy 2008, 36, 4022-4035.

12. Elvidge, C.; Erwin, E.; Baugh, K.; Ziskin, D.; Tuttle, B.; Ghosh, T.; Sutton, P. Overview of DMSP nightime lights and future possibilities. Urban Rem. Sens. Event 2009, doi:10.1109/ URS.2009.5137749.

13. Li, C.; Gibson, J. Are Chinese cities really too small? Rev. Econ. Stud. 2014, 73, 549-576.

14. National Bureau of Statistics (NBS). China City Statistical Yearbook 1994-2013; China Statistics Press: Beijing, China, 2013.

15. Ministry of Public Security (MPS). Population Statistics of the People's Republic of China by County 1993-2012; Qunzhong Press: Beijing, China, 2013.

16. National Bureau of Statistics (NBS). Fifty Years of Cities of New China; China Statistics Press: Beijing, China, 1999.

17. Roberts, M.; Deichmann, U.; Fingleton, B.; Shi, T. Evaluating China's road to prosperity: A new economic geography approach. Reg. Sci. Urban Econ. 2012, 42, 580-594.

18. Welch, R. Monitoring urban population and energy utilization patterns from satellite data. Rem. Sens. Environ. 1980, 9, 1-9.

19. Imhoff, M.; Lawrence, W.; Elvidge, C.; Paul, T.; Levine, E.; Privalsky, M.; Brown, V. Using nighttime DMSP/OLS images of city lights to estimate the impact of urban land use on soil resources in the United States. Rem. Sens. Environ. 1997, 59, 105-117.

20. Small, C.; Pozzi, F.; Elvidge, C. Spatial analysis of global urban extent from DMSP-OLS night lights. Rem. Sens. Environ. 2005, 96, 277-291.

21. Small, C.; Elvidge, C.; Balk, D.; Montgomery, M. Spatial scaling of stable night lights. Rem. Sens. Environ. 2011, 115, 269-280.

22. Henderson, M.; Yeh, E.; Gong, P.; Elvidge, C.; Baugh, K. Validation of urban boundaries derived from global night-time satellite imagery. Int. J. Rem. Sens. 2003, 24, 595-609.

23. Elvidge, C.; Hsu, F.-C.; Baugh, K.; Ghosh, T. National trends in satellite observed lighting: 1992-2012. In Global Urban Monitoring and Assessment through Earth Observation; CRC Press: Boca Raton, FL, USA, 2014; pp. 97-120.

24. Small, C.; Elvidge, C. Night on Earth: Mapping decadal changes of anthropogenic night light in Asia. Int. J. Appl. Earth Obs. 2013, 22, 40-52.

25. Ma, T.; Zhou, C.; Pei, T.; Haynie, S.; Fan, J. Quantitative estimation of urbanization dynamics using time series of DMSP/OLS nighttime light data: A comparative case study from China's cities. Rem. Sens. Environ. 2012, 124, 99-107. 
26. Liu, Z.; He, C.; Zhang, Q.; Huang, Q.; Yang, Y. Extracting the dynamics of urban expansion in China using DMSP-OLS nighttime light data from 1992 to 2008. Landsc. Urban Plan. 2012, 106, $62-72$.

27. Lowe, M. Night Lights and ArcGIS: A Brief Guide. Avaliable online: http://economics.mit.edu/ files/8945 (accessed on 22 August 2014).

28. Elvidge, C.; Ziskin, D.; Baugh, K.; Tuttle, B.; Ghosh, T.; Pack, D.; Erwin, E.; Zhizhin, M. A fifteen year record of global natural gas flaring derived from satellite data. Energies 2009, 2, 595-622.

29. Fan, S.; Li, L.; Zhang, X. Challenges of creating cities in China: Lessons from a short-lived county-to-city upgrading policy. J. Comp. Econ. 2012, 40, 476-491.

30. Li, C.; Gibson, J. Agglomeration economies in China: Locations and effects. 2014, unpublished work.

31. Li, C.; Gibson, J. Rising regional inequality in China: Fact or artifact? World Dev. 2013, 47, 16-29.

32. Huang, J.; Zhi, H.; Huang, J.; Rozelle, S.; Giles, J. The impact of the global financial crisis on off-farm employment and earnings in rural China. World Dev. 2011, 39, 797-807.

(C) 2014 by the authors; licensee MDPI, Basel, Switzerland. This article is an open access article distributed under the terms and conditions of the Creative Commons Attribution license (http://creativecommons.org/licenses/by/4.0/). 